\title{
Characterization of Patients With Type 2 Diabetes and Chronic Kidney Disease in a Large Integrated Health System
}

Kevin Pantalone

Cleveland Clinic

Xinge Ji

Cleveland Clinic

Sheldon Kong

Bayer (United States)

Jay Elliott

Bayer (United States)

Alex Milinovich

Cleveland Clinic

Anita Misra-Hebert

Cleveland Clinic

Ryan Farej

Bayer (United States)

Rakesh Singh

Bayer (United States)

Janine Bauman

Cleveland Clinic

Robert Zimmerman

Cleveland Clinic

Tushar Vachharajani ( $\nabla$ vachhat@ccf.org )

Cleveland Clinic

Jamie Partridge

Bayer (United States)

Jennifer Cameron

Bayer (United States)

Todd Williamson

Bayer (United States)

David Sugano

Cleveland Clinic

Michael Kattan 


\section{Research Article}

Keywords: chronic kidney disease, type 2 diabetes, healthcare resource utilization, albuminuria, electronic health records

Posted Date: December 8th, 2021

DOI: https://doi.org/10.21203/rs.3.rs-1101567/v1

License: (a) (i) This work is licensed under a Creative Commons Attribution 4.0 International License. Read Full License 


\section{Abstract}

Background: Chronic kidney disease (CKD) poses substantial clinical, economic, and humanistic burden in patients with type 2 diabetes (T2D). Understanding of how to optimize patient care and slow disease progression is warranted.

Objective: To compare the prevalence, clinical characteristics, treatment patterns, and healthcare utilization among patients with CKD, T2D, or CKD associated with T2D.

Design: Retrospective cross-sectional analysis.

Patients: Adult patients with CKD, T2D, or CKD+T2D in the Cleveland Clinic Health System.

Main Measures: Clinical characteristics, laboratory measures, medication utilization, cardiometabolic management and healthcare resource utilization.

Key Results: In 2019, 122,276 patients were identified as CKD, 63,643 were identified as T2D, and 35,255 were identified as having CKD associated with T2D. Patients with CKD and CKD+T2D were observed to be older than those with T2D alone, 72.6, 72.2, and 63.0 years, respectively. T2D and T2D+CKD cohorts contained a higher percentage of males vs. those with CKD alone, $49.3 \%, 50.8 \%, 43.6 \%$, respectively. ACEi/ARB therapy was observed in $27.7 \%, 42.4 \%$, and $31.5 \%$ patients with CKD, T2D+CKD, and T2D, respectively. SGLT-2i therapy was only prescribed to a minority of patients with T2D (5.8\%) and T2D+CKD (4.7\%). Emergency department visits and hospital admissions were more prevalent in the group with CKD $(26.5 \%, 52.9 \%)$ or CKD+T2D $(28.8 \%, 54.9 \%)$ vs. T2D alone $(18.6 \%, 41.8 \%)$, respectively. The majority of patients with CKD $(90.4 \%)$, CKD+T2D (60.0\%) or T2D (69.1\%) did not have an assessment of urine protein.

Conclusions: Patients with CKD+T2D or CKD have higher healthcare resource utilization than those with T2D alone. The majority of patients with CKD, CKD+T2D or T2D do not undergo assessment of urine protein and are under prescribed ACEi/ARB therapy. SGLT-2i therapy was prescribed to only a small minority of patients with T2D or CKD+T2D. An opportunity exists to improve the care of patients with CKD, both with and without T2D.

\section{Introduction}

The prevalence of type 2 diabetes is increasing worldwide, and in the United States, the prevalence of diabetes (both type 1 and type 2) is projected to increase by $54 \%$ to more than 54.9 million Americans between 2015 and $2030 .{ }^{1}$ Diabetes can result in a myriad of complications, which are frequently categorized as micro- or macrovascular. Kidney damage, which may ultimately result in chronic kidney disease, is one such microvascular complication of diabetes. The development and progression of chronic kidney disease is multifactorial, with metabolic, hemodynamic, inflammatory and fibrotic drivers contributing to the progressive decline in kidney function that is typically observed in patients with and 
without type 2 diabetes. ${ }^{2-7}$ The substantial clinical, economic, and humanistic burden of kidney disease is well-documented in the literature with approximately $50 \%$ of end-stage kidney disease cases caused by diabetes in the developed world. ${ }^{8}$ Given the public health magnitude, and recent advancements in medical therapy for patients with chronic kidney disease ${ }^{4-6}$, it is important to understand the prevalence of chronic kidney disease in patients with type 2 diabetes and their clinical characteristics to inform opportunities to optimize outcomes. Previous studies have leveraged National Health and Nutrition Examination Survey (NHANES) data to evaluate the prevalence of chronic kidney disease in the type 2 diabetes population. These studies have resulted in sobering U.S. prevalence estimates of $38-44 \% .{ }^{9-11}$

Patients with type 2 diabetes and chronic kidney disease have a high mortality rate and increased cardiovascular events ${ }^{12}$, and can progress to end stage kidney disease. The annual mortality rate for patients with diabetes and kidney failure has been reported to be 64.1 per 1000 individuals and increases with severity of chronic kidney disease [Stage 3A (37.0), Stage 3B (57.5), Stage 4 (98.3) and Stage 5

(98.5)]. ${ }^{13}$ Patients with type 2 diabetes similarly have an increased risk of cardiovascular disease. The objective of this study was to characterize patients with type 2 diabetes and/or chronic kidney disease in terms of demographics, medication utilization and healthcare resource use in a contemporary real-world setting, so as to identify opportunities to improve the quality of care rendered to these populations and reduce their risk of adverse cardiovascular and kidney outcomes.

\section{Methods}

This retrospective cross-sectional analysis was conducted using the enterprise-wide electronic health record (EHR) at Cleveland Clinic Health System (CCHS), was approved by the Institutional Review Board of Cleveland Clinic and informed consent was waived. All methods were carried out in accordance with relevant guidelines and regulations. The study sample was a cohort of patients with chronic kidney disease, chronic kidney disease+type 2 diabetes or type 2 diabetes without documented chronic kidney disease, established using EHR data from 2005 to 2019 in the CCHS. Patients from this cohort and included in the study were required to have at least one outpatient visit in 2019 and at least two outpatient visits with a primary care, endocrinology, nephrology, or cardiology provider (any combination) during or prior to 2019. These provider types were selected as they are expected to most actively participate in the management of patients with chronic kidney disease and/or type 2 diabetes, and because these two conditions are associated with a higher risk of developing cardiovascular disease. The patient attrition flowchart (Figure 1) depicts how the patients were classified, and the order by which their chronic kidney disease and type 2 diabetes diagnosis was identified.

\section{Identification of chronic kidney disease patients}

The chronic kidney disease study cohort was created using ICD-9/-10 codes and laboratory measures. The earliest date when a patient record met any of the following combinations was documented as the date in which the patient met the criteria for chronic kidney disease: 1) two eGFR $<90$ separated by more 
than 90 days, 2) ICD-9/-10 codes (E11.21, E11.22, 250.4, NO[0-7].[2-7], 58[0-3].[012489].X, I12.X, 403.X, Q61.Q, 753.1X, N18.X, 585.X) and 3) two urine albumin:creatinine ratio of $>30 \mathrm{mg} / \mathrm{g}$ OR urine protein:creatinine ratio $>150 \mathrm{mg} / \mathrm{g}$, separated by more than 90 days. Combinations preceded by a type 2 diabetes code, type 2 diabetes medication, A1C $>6.5 \%$ or blood glucose $>200 \mathrm{mg} / \mathrm{dL}$ were excluded. Patients with records at any time indicating other types of diabetes (including the following) were also excluded: 1) Type 1 diabetes (ICD-9 codes: 250.x1, 250.x3; ICD-10 code: E10), 2) Diabetes mellitus due to an underlying condition (ICD-9 code: 249; ICD-10 code: E08), 3) Drug or chemical induced diabetes mellitus (ICD-9 code: 249; ICD-10 code: E09), and 4) Other specified diabetes mellitus: (ICD-9 code: 249; ICD-10 code: E13).

\section{Identification of type 2 diabetes patients}

The type 2 diabetes study cohort was created based upon ICD-9/-10 codes (250X, E11X). A modified version of the EMERGE algorithm ${ }^{7}$ was used to calculate the earliest date when a patient record contained any of the following combinations: 1 ) type 2 diabetes code and type 2 diabetes medication, 2) type 2 diabetes code and abnormal glucose, 3) type 2 diabetes code recorded twice and outpatient insulin, 4) type 2 diabetes medication and abnormal glucose and 5) outpatient insulin preceded by type 2 diabetes medication. The earliest date that any of the five conditions above were met was documented as the date in which the patient met the criteria for type 2 diabetes. Patients with records at any time indicating other types of diabetes (including the following) were excluded: 1) Type 1 diabetes (ICD-9 codes: 250.x1, 250.x3; ICD-10 code: E10), 2) Diabetes mellitus due to underlying condition (ICD-9 code: 249; ICD-10 code: E08), 3) Drug or chemical induced diabetes mellitus (ICD-9 code: 249; ICD-10 code: E09), and 4) Other specified diabetes mellitus: (ICD-9 code: 249; ICD-10 code: E13). Combinations preceded by an ICD-9/-10 codes used for chronic kidney disease, two eGFR $<90$, one urine albumin to creatinine ratio of $>30 \mathrm{mg} / \mathrm{g}$ or urine protein creatinine ratio $>150 \mathrm{mg} / \mathrm{g}$ were also excluded.

\section{Identification of chronic kidney disease + type 2 diabetes patients}

The chronic kidney disease+type 2 diabetes cohort was created based upon the definitions for the chronic kidney disease and type 2 diabetes only cohorts outlined above. Patients must have met both inclusion criteria.

\section{Outcome Measures}

Demographic characteristics, clinical characteristics, laboratory measures, medication utilization, cardiometabolic management and healthcare resource utilization were summarized during 2019 and compared between patients that had chronic kidney disease alone, type 2 diabetes alone, or chronic kidney disease+type 2 diabetes. Demographic and clinical characteristics, and medication utilization were assessed at the last documented encounter in 2019. Outpatient type 2 diabetes therapies documented within the patients' medication list in 2019 were also recorded. Continuous variables were reported as medians with interquartile ranges (IQRs) or mean +/-SD (where appropriate) and as $\mathrm{N}(\%)$ for categorical variables. Medians were reported with IQRs because these continuous variables were not 
normally distributed. The Kruskal-Wallis rank sum test was used to compare continuous variables and the chi-square test was used for categorical variables with a significance level of $p<0.05$. The null hypotheses were that the variables in all 3 groups have equal medians for continuous variables, or equal frequencies for categorical variables.

\section{Results}

In 2019 , of the $1,774,807$ patients within the Cleveland Clinic Health System, 122,276 patients were identified as chronic kidney disease only, 63,643 were identified as type 2 diabetes only, and 35,255 were identified as having both chronic kidney disease+type 2 diabetes (Table 1). P-values for all of the outlined comparisons were $<0.001$. 
Table 1

Descriptive Analysis of the Chronic Kidney Disease, Chronic Kidney Disease +Type 2 Diabetes, and Type 2 Diabetes Retrospective Cohorts as of 2019*

\begin{tabular}{|c|c|c|c|c|}
\hline & $\begin{array}{l}\text { Chronic } \\
\text { Kidney } \\
\text { Disease only }\end{array}$ & $\begin{array}{l}\text { Chronic Kidney } \\
\text { Disease+Type } 2 \\
\text { Diabetes }\end{array}$ & $\begin{array}{l}\text { Type } 2 \\
\text { Diabetes } \\
\text { Only }\end{array}$ & $\begin{array}{l}P \text { - } \\
\text { value }\end{array}$ \\
\hline \multicolumn{5}{|l|}{ Demographics } \\
\hline $\mathrm{N}$ & 122276 & 35255 & 63643 & \\
\hline Age (years) & $\begin{array}{l}72.64[62.52, \\
81.70]\end{array}$ & $72.23[64.01,79.70]$ & $\begin{array}{l}\text { 63.00 [53.91, } \\
71.21]\end{array}$ & $<0.001$ \\
\hline Male (\%) & $53277(43.6)$ & $17926(50.8)$ & $31349(49.3)$ & $<0.001$ \\
\hline Ethnicity (\%) & & & & $<0.001$ \\
\hline Hispanic & $4453(3.6)$ & $1625(4.6)$ & $3756(5.9)$ & \\
\hline Not Hispanic or Latino & 114437 (93.6) & $32642(92.6)$ & $57434(90.2)$ & \\
\hline Unknown & $3386(2.8)$ & $988(2.8)$ & $2453(3.9)$ & \\
\hline Race (\%) & & & & $<0.001$ \\
\hline Asians & $926(0.8)$ & $411(1.2)$ & $1206(1.9)$ & \\
\hline Black & $15729(12.9)$ & $6333(18.0)$ & 10977 (17.2) & \\
\hline Caucasian & $100802(82.4)$ & $26655(75.6)$ & $47163(74.1)$ & \\
\hline Other & 4819 (3.9) & $1856(5.3)$ & $4297(6.8)$ & \\
\hline Insurance (\%) & & & & $<0.001$ \\
\hline Commercial & $27643(22.6)$ & $6679(18.9)$ & $25232(39.6)$ & \\
\hline Medicaid & $6081(5.0)$ & $1916(5.4)$ & $6158(9.7)$ & \\
\hline Medicare & $83825(68.6)$ & $25147(71.3)$ & $27638(43.4)$ & \\
\hline Other & 4727 ( 3.9$)$ & $1513(4.3)$ & 4615 ( 7.3$)$ & \\
\hline \multirow[t]{2}{*}{ Median Income } & 62710.00 & 55988.00 & 55740.00 & $<0.001$ \\
\hline & $\begin{array}{l}{[46873.00} \\
78924.00]\end{array}$ & $\begin{array}{l}{[45474.00} \\
72122.00]\end{array}$ & $\begin{array}{l}{[45474.00} \\
71194.00]\end{array}$ & \\
\hline \multicolumn{5}{|l|}{ Clinical Characteristics } \\
\hline BMI $\left(\mathrm{kg} / \mathrm{m}^{2}\right)$ & $\begin{array}{l}27.73[24.33 \\
31.91]\end{array}$ & $31.23[27.24,36.30]$ & $\begin{array}{l}32.44[28.24 \\
37.71]\end{array}$ & $<0.001$ \\
\hline
\end{tabular}

*Continuous variables were reported as medians with interquartile ranges and categorical variables as numbers and percentages. 


\begin{tabular}{|c|c|c|c|c|}
\hline & $\begin{array}{l}\text { Chronic } \\
\text { Kidney } \\
\text { Disease only }\end{array}$ & $\begin{array}{l}\text { Chronic Kidney } \\
\text { Disease+Type } 2 \\
\text { Diabetes }\end{array}$ & $\begin{array}{l}\text { Type } 2 \\
\text { Diabetes } \\
\text { Only }\end{array}$ & $\begin{array}{l}\mathrm{P}- \\
\text { value }\end{array}$ \\
\hline Systolic Blood Pressure (mmHg) & $\begin{array}{l}129.33 \\
{[120.83} \\
138.00]\end{array}$ & $\begin{array}{l}130.88[123.00 \\
139.33]\end{array}$ & $\begin{array}{l}129.60 \\
{[122.00} \\
138.00]\end{array}$ & $<0.001$ \\
\hline Diastolic Blood Pressure (mmHg) & $\begin{array}{l}72.50[66.80 \\
78.29]\end{array}$ & $71.50[65.78,77.33]$ & $\begin{array}{l}75.00[69.00 \\
80.29]\end{array}$ & $<0.001$ \\
\hline $\begin{array}{l}\text { History of Cardiovascular } \\
\text { Disease (\%) }\end{array}$ & $18168(14.9)$ & $6468(18.3)$ & $5537(8.7)$ & $<0.001$ \\
\hline eGFR $\left(\mathrm{mL} / \mathrm{min} / 1.73 \mathrm{~m}^{2}\right)$ & $\begin{array}{l}58.81[48.08 \\
70.90]\end{array}$ & $59.18[45.85,74.73]$ & $\begin{array}{l}89.40[78.30 \\
100.40]\end{array}$ & $<0.001$ \\
\hline \multicolumn{5}{|l|}{ Labs } \\
\hline Potassium (mmol/L) & $\begin{array}{l}4.30[4.00 \\
4.60]\end{array}$ & $4.30[4.00,4.60]$ & $\begin{array}{l}4.20[3.90, \\
4.50]\end{array}$ & $<0.001$ \\
\hline Creatinine (mg/dL) & $\begin{array}{l}1.09[0.90 \\
1.32]\end{array}$ & $1.15[0.91,1.46]$ & $\begin{array}{l}0.81[0.69 \\
0.96]\end{array}$ & $<0.001$ \\
\hline LDL (mg/dL) & $\begin{array}{l}94.50[73.00 \\
119.00]\end{array}$ & $\begin{array}{l}83.00[61.00 \\
110.25]\end{array}$ & $\begin{array}{l}89.00[67.00 \\
113.00]\end{array}$ & $<0.001$ \\
\hline Triglyceride (mg/dL) & $\begin{array}{l}100.00[73.00 \\
141.00]\end{array}$ & $\begin{array}{l}127.00[91.00 \\
177.00]\end{array}$ & $\begin{array}{l}125.00 \\
{[88.00} \\
179.75]\end{array}$ & $<0.001$ \\
\hline $\mathrm{HDL}(\mathrm{mg} / \mathrm{dL})$ & $\begin{array}{l}52.00[43.00 \\
64.00]\end{array}$ & $44.00[36.00,53.00]$ & $\begin{array}{l}45.00[37.00 \\
54.00]\end{array}$ & $<0.001$ \\
\hline A1C (\%) & $\begin{array}{l}5.60[5.40 \\
5.90]\end{array}$ & $6.60[6.10,7.50]$ & $\begin{array}{l}6.60[6.10, \\
7.50]\end{array}$ & $<0.001$ \\
\hline Alb:Cr (mg/g) & $\begin{array}{l}53.00[21.30 \\
188.00]\end{array}$ & $\begin{array}{l}51.00[21.00 \\
135.00]\end{array}$ & $\begin{array}{l}16.00[10.00 \\
29.00]\end{array}$ & $<0.001$ \\
\hline Missing Alb:Cr (\%) & $121419(99.3)$ & $33393(94.7)$ & $62051(97.3)$ & \\
\hline $\begin{array}{l}\text { Missing Urine Alb:Cr or Protein:Cr } \\
(\%)\end{array}$ & 112935 (92.4) & $24608(69.8)$ & $50876(79.9)$ & \\
\hline $\begin{array}{l}\text { Missing Urine Alb:Cr, random } \\
\text { Urine Albumin, and Urine } \\
\text { Protein:Cr (\%) }\end{array}$ & $110493(90.4)$ & $21159(60.0)$ & $43974(69.1)$ & \\
\hline \multicolumn{5}{|l|}{ Medications } \\
\hline Receiving Antihypertensive Agent & $73259(59.9)$ & $25524(72.4)$ & $34358(54.0)$ & $<0.001$ \\
\hline ARB or ACEi & $33859(27.7)$ & $14955(42.4)$ & $20023(31.5)$ & $<0.001$ \\
\hline
\end{tabular}




\begin{tabular}{|c|c|c|c|c|}
\hline & $\begin{array}{l}\text { Chronic } \\
\text { Kidney } \\
\text { Disease only }\end{array}$ & $\begin{array}{l}\text { Chronic Kidney } \\
\text { Disease+Type } 2 \\
\text { Diabetes }\end{array}$ & $\begin{array}{l}\text { Type } 2 \\
\text { Diabetes } \\
\text { Only }\end{array}$ & $\begin{array}{l}\mathrm{P}- \\
\text { value }\end{array}$ \\
\hline $\mathrm{N}$ of Antihypertensive Agents & $\begin{array}{l}1.00[0.00 \\
2.00]\end{array}$ & $1.00[0.00,3.00]$ & $\begin{array}{l}1.00[0.00 \\
2.00]\end{array}$ & $<0.001$ \\
\hline $\begin{array}{l}\text { Receiving Antihyperglycemic } \\
\text { Agent }\end{array}$ & $5294(4.3)$ & $24702(70.1)$ & $50933(80.0)$ & $<0.001$ \\
\hline $\mathrm{N}$ of Antihyperglycemic Agents & $\begin{array}{l}0.00[0.00 \\
0.00]\end{array}$ & $1.00[0.00,2.00]$ & $\begin{array}{l}1.00[0.00 \\
2.00]\end{array}$ & $<0.001$ \\
\hline $\begin{array}{l}\text { Receiving Antihyperlipidemic } \\
\text { Agent }\end{array}$ & $42897(35.1)$ & $18370(52.1)$ & $25902(40.7)$ & $<0.001$ \\
\hline $\mathrm{N}$ of Antihyperlipidemics Agents & $\begin{array}{l}0.00[0.00 \\
1.00]\end{array}$ & $1.00[0.00,1.00]$ & $\begin{array}{l}0.00[0.00 \\
1.00]\end{array}$ & $<0.001$ \\
\hline SGLT-2i & $102(0.1)$ & $1661(4.7)$ & $3718(5.8)$ & $<0.001$ \\
\hline \multicolumn{5}{|l|}{ Healthcare Resource Utilization } \\
\hline ED Visits (yes) & $32395(26.5)$ & $10151(28.8)$ & $11820(18.6)$ & $<0.001$ \\
\hline ED Visits N (mean, SD) & $0.80(2.08)$ & $0.88(2.19)$ & $0.55(2.12)$ & $<0.001$ \\
\hline Hospital Admission (yes) & $64625(52.9)$ & $19351(54.9)$ & $26613(41.8)$ & $<0.001$ \\
\hline $\begin{array}{l}\text { Hospital Admission N (median, } \\
\text { IQR) }\end{array}$ & $\begin{array}{l}1.00[0.00 \\
2.00]\end{array}$ & $1.00[0.00,3.00]$ & $\begin{array}{l}0.00[0.00 \\
2.00]\end{array}$ & $<0.001$ \\
\hline $\begin{array}{l}\text { Hospital Admission N (mean, } \\
\text { SD) }\end{array}$ & $2.08(4.34)$ & $2.42(4.95)$ & $1.39(3.19)$ & $<0.001$ \\
\hline Outpatient Office Visits (yes) & $108092(88.4)$ & 30974 (87.9) & $55310(86.9)$ & $<0.001$ \\
\hline $\begin{array}{l}\text { Outpatient Office Visits N } \\
\text { (median, IQR) }\end{array}$ & $\begin{array}{l}8.00[3.00 \\
18.00]\end{array}$ & $9.00[3.00,19.00]$ & $\begin{array}{l}5.00[2.00 \\
12.00]\end{array}$ & $<0.001$ \\
\hline $\begin{array}{l}\text { Outpatient Office Visits N (mean, } \\
\text { SD) }\end{array}$ & $13.79(18.04)$ & $14.58(18.55)$ & $9.17(12.73)$ & $<0.001$ \\
\hline $\begin{array}{l}\text { Endocrinology Department Visit } \\
\text { (yes) }\end{array}$ & $4375(3.6)$ & $3036(8.6)$ & $5729(9.0)$ & $<0.001$ \\
\hline $\begin{array}{l}\text { Endocrinology Department N } \\
\text { (mean, SD) }\end{array}$ & $0.08(0.64)$ & $0.22(0.99)$ & $0.24(1.08)$ & $<0.001$ \\
\hline Nephrology Department (yes) & $9329(7.6)$ & $2696(7.6)$ & $270(0.4)$ & $<0.001$ \\
\hline $\begin{array}{l}\text { Nephrology Department N (mean, } \\
\text { SD) }\end{array}$ & $0.17(0.85)$ & $0.17(0.80)$ & $0.01(0.12)$ & $<0.001$ \\
\hline Primary Care Visit (yes) & $78524(64.2)$ & $21842(62.0)$ & $37852(59.5)$ & $<0.001$ \\
\hline
\end{tabular}




\begin{tabular}{|lllll|}
\hline & $\begin{array}{l}\text { Chronic } \\
\text { Kidney } \\
\text { Disease only }\end{array}$ & $\begin{array}{l}\text { Chronic Kidney } \\
\text { Disease+Type 2 } \\
\text { Diabetes }\end{array}$ & $\begin{array}{l}\text { Type 2 } \\
\text { Diabetes } \\
\text { Only }\end{array}$ & $\begin{array}{l}\text { P- } \\
\text { value }\end{array}$ \\
\hline Primary Care N (median, IQR) & $\begin{array}{l}2.00[0.00, \\
6.00]\end{array}$ & $2.00[0.00,7.00]$ & $\begin{array}{l}1.00[0.00, \\
4.00]\end{array}$ & $<0.001$ \\
\hline Primary Care N (mean, SD) & $4.77(7.77)$ & $4.96(8.06)$ & $3.40(5.86)$ & $<0.001$ \\
\hline $\begin{array}{l}\text { Cardiology Department Visit } \\
\text { (yes) }\end{array}$ & $36009(29.4)$ & $11345(32.2)$ & $13245(20.8)$ & $<0.001$ \\
\hline $\begin{array}{l}\text { Cardiology Department N (mean, } \\
\text { SD) }\end{array}$ & $1.17(3.96)$ & $1.40(4.72)$ & $0.71(2.97)$ & $<0.001$ \\
\hline $\begin{array}{l}\text { *Continuous variables were reported as medians with interquartile ranges and categorical variables } \\
\text { as numbers and percentages. }\end{array}$ & & & & \\
\hline
\end{tabular}

\section{Demographics}

Patients with chronic kidney disease and chronic kidney disease+type 2 diabetes were observed to be older (years) than those with type 2 diabetes alone, 72.6, 72.2, and 63.0, respectively. Patient cohorts with type 2 diabetes and chronic kidney disease+type 2 diabetes contained a higher percentage of males compared to those with chronic kidney disease alone, $49.3 \%, 50.8 \%, 43.6 \%$, respectively. The proportion of Hispanic and black patients was more prevalent in the type 2 diabetes $(5.9 \%, 17.2 \%)$ and chronic kidney disease+type 2 diabetes $(4.6 \%, 18.0 \%)$ groups, than those with chronic kidney disease alone $(3.6 \%$, $12.9 \%)$. Medicare insurance coverage was higher in the group of patients with chronic kidney disease (68.6\%) and chronic kidney disease+type 2 diabetes (71.3\%) vs. those with type 2 diabetes alone (43.4\%). Median household income was significantly higher in the group with chronic kidney disease only $(\$ 62,710)$ vs. those with chronic kidney disease+type 2 diabetes $(\$ 55,988)$ or type 2 diabetes alone $(\$ 55,740)$.

\section{Clinical Characteristics and Labs}

Patients with type 2 diabetes and chronic kidney disease+type 2 diabetes were observed to have a higher median BMI (kg/m2) than those with chronic kidney disease alone, 32.4, 31.2, and 27.7, respectively. A history of cardiovascular disease was observed in $14.9 \%, 18.3 \%$, and $8.7 \%$ of patients with chronic kidney disease alone, chronic kidney disease+type 2 diabetes, and type 2 diabetes alone, respectively. Although statistical variations in median systolic and diastolic blood pressure were observed, they were small and not considered clinically relevant. As expected, median A1C values were observed to be higher in those with type 2 diabetes and chronic kidney disease+type 2 diabetes, and median creatinine values were observed to be higher in those with chronic kidney disease and chronic kidney disease+type 2 diabetes. The median potassium levels ( $\mathrm{mmol} / \mathrm{L}$ ) were similar among those with chronic kidney disease, chronic kidney disease+type 2 diabetes or type 2 diabetes, 4.3, 4.3, 4.2, respectively. Median HDL (mg/dL) was higher, and $\mathrm{Tg}(\mathrm{mg} / \mathrm{dL})$ levels lower, in those with chronic kidney disease vs. those with chronic kidney 
disease+type 2 diabetes or type 2 diabetes, (52.0, 100.0; 44.0 127.0; 45.0, 125.0), respectively. Median $\mathrm{LDL}(\mathrm{mg} / \mathrm{dL})$ was higher in those with chronic kidney disease vs. chronic kidney disease+type 2 diabetes or type 2 diabetes, $94.5,83.0,89.0$, respectively. Median eGFR $\left(\mathrm{mL} / \mathrm{min} / 1.73 \mathrm{~m}^{2}\right)$ in the chronic kidney disease and chronic kidney disease+type 2 diabetes was lower compared to those with type 2 diabetes, $58.8,59.2$, and 84.9 respectively. The median urine albumin:creatinine $(\mathrm{alb}: \mathrm{Cr}, \mathrm{mg} / \mathrm{g}$ ) ratio was higher in those with chronic kidney disease and chronic kidney disease+type 2 diabetes compared to those with type 2 diabetes, 53.0, 51.0, 16.0, respectively. However, the majority of patients with chronic kidney disease alone (92.4\%), chronic kidney disease+type 2 diabetes $(69.8 \%)$ or type 2 diabetes alone $(79.9 \%)$ did not have any assessment of urine protein (protein:Cr or alb:Cr) documented in 2019.

\section{Medications}

Antihypertensive therapy was more prevalent in those with chronic kidney disease+type 2 diabetes (72.4\%) vs. those with chronic kidney disease $(59.9 \%)$ or type 2 diabetes $(54.4 \%)$ alone. Antihyperlipidemic therapy was also observed to be more prevalent in those with chronic kidney disease+type 2 diabetes (52.1\%) or type 2 diabetes (40.7\%) vs. chronic kidney disease (35.1\%) alone. As expected, antihyperglycemic therapy was more prevalent in those with chronic kidney disease+type 2 diabetes $(70.1 \%)$ or type 2 diabetes (80.0\%) vs. chronic kidney disease (4.3\%). ACEi/ARB therapy was observed in $27.7 \%, 42.4 \%$, and $31.5 \%$ patients with chronic kidney disease alone, chronic kidney disease+type 2 diabetes, and type 2 diabetes alone, respectively. SGLT-2i therapy was only prescribed to a minority of patients with type 2 diabetes (5.8\%), chronic kidney disease+type 2 diabetes (4.7\%), and chronic kidney disease (0.1\%).

\section{Healthcare Resource Utilization}

The percentage of patients with at least one outpatient visit in 2019 was high among all cohorts, with group percentages of $88.4 \%$ in patients with chronic kidney disease, $87.9 \%$ with chronic kidney disease+type 2 diabetes, or $86.9 \%$ with type 2 diabetes. The median number of outpatient visits was observed to be higher in those with chronic kidney disease+type 2 diabetes (9.0) or chronic kidney disease (8.0) vs. type 2 diabetes (5.0). The prevalence of primary care visits was similar across groups, but statistically higher in those with chronic kidney disease (64.2\%) or chronic kidney disease+type 2 diabetes (62.0) vs. type 2 diabetes (59.5\%).

Emergency department visits and hospital admissions were more prevalent in the group with chronic kidney disease or chronic kidney disease+type 2 diabetes compared to type 2 diabetes alone; $26.5 \%$, $52.9 \% ; 28.8 \%, 54.9 \% ; 18.6 \%, 41.8 \%$, respectively. Cardiology visits were more prevalent in those with chronic kidney disease (29.4\%) and chronic kidney disease+type 2 diabetes (32.2\%) compared to those with type 2 diabetes (20.8\%). Endocrinology visits were more common in those with type 2 diabetes $(9.0 \%)$ or chronic kidney disease+type 2 diabetes (8.6\%) vs. chronic kidney disease (3.6\%), and nephrology visits were more common in those with chronic kidney disease $(7.6 \%)$ or chronic kidney disease+type 2 diabetes (7.6\%) vs. type 2 diabetes (0.4\%). 


\section{Discussion}

The results confirm the large clinical and economic burden of chronic kidney disease, particularly in patients with type 2 diabetes. Patients were observed to be "sicker" and used more healthcare resources in the ascending order of: type 2 diabetes < chronic kidney disease < chronic kidney disease+type 2 diabetes. This observation may be in part related to the older age (years) observed among those with chronic kidney disease alone (72.6) or chronic kidney disease+type 2 diabetes (72.2) vs. type 2 diabetes alone (63.0). Emergency department visits and hospitalizations were highest in those with both chronic kidney disease+type 2 diabetes. While the percentage of patients with a primary care visit was observed to be very similar across groups, more patients with chronic kidney disease and type 2 diabetes had cardiology visits, not surprising since the prevalence of cardiovascular disease was observed to be highest in this group (18.3\%). The prevalence of other specialty visits was observed to be rather low. Nephrology visits were observed in only $7.6 \%$ of patients with chronic kidney disease or chronic kidney disease+type 2 diabetes, and endocrinology visits were observed in only $9.0 \%$ and $8.6 \%$ of patients with type 2 diabetes or chronic kidney disease+type 2 diabetes respectively. Perhaps a higher rate of specialty referral and management, as well as an increase in outpatient primary care visits, would lead to a reduction in the number of emergency department visits and hospitalizations in patients with chronic kidney disease+type 2 diabetes.

The utilization of ACEi/ARB therapy was observed to be low in our cohorts of patients with chronic kidney disease alone (27.7\%), chronic kidney disease+type 2 diabetes (42.4\%), and type 2 diabetes alone (31.5\%). This is much lower than has been previously reported by Vupputuri et.al. with $54-65 \%$ depending on the stage of chronic kidney disease ${ }^{14}$, but similar to other reports which have characterized the utilization of ACEi or ARB therapy among patients with type 2 diabetes ${ }^{15,16}$ Low ACEi/ARB use in chronic kidney disease alone may be explained, in part, by non-diabetic kidney disease or chronic kidney disease without proteinuria or resulting hyperkalemia. In addition, prescriptions for SGLT-2i therapy in patients with type 2 diabetes or chronic kidney disease+type 2 diabetes were observed to be rather low, and only modestly higher when compared to data from 2017. ${ }^{15}$ Lastly, the assessment of proteinuria was observed to be disappointingly low among our three cohorts of patients, and this is consistent with data that has been previously published. ${ }^{17}$ These observations highlight the opportunity that exits to improve the frequency of albuminuria testing to guideline-recommended standards since albuminuria levels are highly predictive of all-cause mortality, end stage kidney disease and risk of fatal and non-fatal cardiovascular events. ${ }^{18,19}$ Dedicated kidney outcome randomized controlled trials have demonstrated the benefits of SGLT-2is ${ }^{4,5}$ and the non-steroidal mineralocorticoid antagonist finerenone ${ }^{6}$ on the risk of chronic kidney disease progression and associated outcomes, particularly in patients with type 2 diabetes. Thus, recognizing the presence of chronic kidney disease in patients with type 2 diabetes will become ever-more important, and the choice of therapies will need to include those which may provide additional benefits, beyond those afforded by adequate blood pressure and glycemic control, as well as ACEi/ARB therapy. 
The strengths of this study include the large number of participants identified, the use of the validated EMERGE algorithm to properly identify patients with type 2 diabetes, and the robust amount of clinical data which allowed for an extensive depiction of subjects. While there are numerous strengths of our analysis, it is not without limitations. Our study is limited by its use of only structured data to document both chronic kidney disease and type 2 diabetes, which relies heavily on provider coding practices and adequate documentation of lab results which may have occurred outside our health system. Adding the use of natural language processing of chart notes may better capture these disease states vs. using the ICD codes alone. In addition, our record of medication utilization was based upon EHR documentation of prescriptions, not based on pharmacy data; thus, medication compliance could not be ascertained. As is typical of cross-sectional data in general, full interpretation of the observed medication use and comorbidity burden is limited by the lack of longitudinal data. Further, cross-sectional data cannot capture the complexities of clinical care on a patient level. However, our intent was primarily to understand the prevalence of these conditions and overall care patterns in a large cohort of patients with both type 2 diabetes and chronic kidney disease, purposes for which cross sectional data are particularly useful. While we limited our analysis to active patients in our health system by requiring at least one outpatient encounter in 2019, this likely resulted in bias by selecting "sicker" patients as they are the ones likely to seek or require care. Lastly, our report only contains data from one integrated delivery system so generalizability of our findings may be limited.

Characterizing the population of patients with chronic kidney disease and type 2 diabetes will become ever-more important in routine clinical practice to ensure that appropriate treatment strategies are initiated. A tremendous opportunity exists to improve the utilization of ACEi or ARB therapy, particularly in patients with chronic kidney disease or chronic kidney disease+type 2 diabetes. In addition, routine measurement of urine protein, particularly urine albumin to creatinine ratio, was observed to be very low. For type 2 diabetes patients, guidelines recommend at least annual urine albumin to creatinine ratio testing to thoroughly characterize the chronic kidney disease burden and to monitor for chronic kidney disease progression. Furthermore, employing strategies to mitigate chronic kidney disease progression may help to offset costs associated with the disease thereby freeing up resources for other high valued needs. This study, leveraging real-world data, helps to expand our knowledge about the burden of chronic kidney disease in patients with and without type 2 diabetes and the opportunities that exist to improve the quality of care rendered to these populations.

\section{Declarations}

\section{ACKNOWLEDGEMENTS}

Funding for this research was provided by Bayer US LLC.

\section{CONFLICT OF INTEREST SUMMARY}

Dr. Pantalone reported personal fees (consultant) from Bayer for the submitted work, and research support (grants) and personal fees (consulting honoraria) from Bayer, personal fees (consulting and 
speaker honoraria) from AstraZeneca, personal fees (consulting honoraria) from Sanofi, personal fees (consulting and speaker honoraria) from Corcept Therapeutics, personal fees (consulting honoraria) from Eli Lilly, and research support (grants) and personal fees (consulting and speaker honoraria) from Novo Nordisk and Merck \& Co, outside the submitted work.

Dr. Kattan reported a grant from Bayer for the submitted work, and a grant from Novo Nordisk outside the submitted work.

Mr. Milinovich reported grants from Novo Nordisk, Merck, Boehringer Ingelheim, and Bayer during the conduct of the study, and a grant from the NIH outside the submitted work.

Dr. Zimmerman, Dr. Sugano, and Ms. Bauman reported research support or a grant from Bayer for the submitted work.

Dr. Misra-Hebert reported funding from the Agency for Healthcare Research and Quality and grants from the National Heart Lung and Blood Institute, the National Human Genome Research Institute, Novo Nordisk, Inc., Merck Inc., and Boehringer Ingelheim Pharmaceuticals, Inc., outside the submitted work.

Dr. Vachharajani and Ms. Ji reported no conflicts of interest.

Drs. Kong, Singh, Elliott, Partridge, Williamson and Mr. Farej and Ms. Cameron are employed by Bayer, which provided support for this study.

\section{References}

1. Rowley WR, Bezold C, Arikan Y, Byrne E, Krohe S. Diabetes 2030: insights from yesterday, today, and future trends. Popul Health Manag. 2017;20(1):6-12.

2. Alicic RZ, Rooney MT, Tuttle KR.Diabetic kidney disease challenges, progress, and possibilities. Clin J Am Soc Nephrol. 2017;12(12):2032-2045.

3. Brenner B, Cooper ME, de Zeeuw D et al. Effects of losartan on renal and cardiovascular outcomes in patients with type 2 diabetes and nephropathy. N Engl J Med. 2001;345(12):861-869.

4. Perkovic V, Jardine MJ, Neal B et al. Canagliflozin and renal outcomes in type 2 diabetes and nephropathy. N Engl J Med. 2019;380(24):2295-2306.

5. Heerspink HJL, Stefansson BV, Correa-Rotter R et al. Dapagliflozin in patients with chronic kidney disease. N Engl J Med 2020; 383:1436-1446

6. Bakris GL, Agarwal R, Anker SD et al. Effect of finerenone on chronic kidney disease outcomes in type 2 diabetes. N Engl J Med 2020; 383:2219-2229.

7. Bauersachs J, Jaisser F, Toto R. Mineralocorticoid receptor activation and mineralocorticoid receptor antagonist treatment in cardiac and renal diseases. Hypertension. 2015;65(2)257-263.

8. Tuttle KR, Bakris GL, Bilous RW et al. Diabetic kidney disease: a report from an ADA Consensus Conference. Diabetes Care. 2014;37:2864-83. 
9. Bailey RA, Wang Y, Zhu V, Rupnow MFT. Chronic kidney disease in US adults with type 2 diabetes: an updated national estimate of prevalence based on kidney disease: improving global outcomes (KDIGO) stages. BMC Research Notes. 2014;7:415.

10. Wu B, Bell K, Stanford A et al. Understanding CKD among patients with T2DM: prevalence, temporal trends, and treatment patterns - NHANES 2007-2012. BMJ Open Diabetes Research and Care. 2016;4:e000154.

11. Afkarian M, Zelnick LR, Hall YN et al. Clinical manifestations of kidney disease among US adults with diabetes, 1988-2014. JAMA. 2016;316(6):602-610.

12. Afkarian $M$, Sachs $M C$, Kestenbaum $B$ et al. Kidney disease and increased mortality risk in type 2 diabetes. J AM Soc Nephrol 2013; 24: 302-8.

13. Ang YG, Heng BH, Saxena N, Liew STA, Chong P Annual all-cause mortality rate for patients with diabetic kidney disease in Singapore. J Clin Transl Endorinol. 2016; 4:1-6.

14. Vupputuri S, Kimes TM, Calloway MO et al. The economic burden of progressive chronic kidney disease among patients with type 2 diabetes. J Diabetes Complications 2014;28: 10-6.

15. Zhou Z, Chaudhari P, Yang $\mathrm{H}$ et al. Healthcare resource use, costs, and disease progression associated with diabetic nephropathy in adults with type 2 diabetes: a retrospective observational study. Diabetes Ther. 2017; 8:555-71.

16. Nissenson AR, Collins AJ, Hurley J, Petersen H, Pereira BJ, Steinberg EP. Opportunities for improving the care of patients with chronic renal insufficiency: current practice patterns. J Am Soc Nephrol 2001;12: 1713-20.

17. Tuttle KR, Alicic RZ, Duru OK et al. Clinical characteristics of and risk factors for chronic kidney disease among adults and children an analysis of the CURE-CKD registry. JAMA Network Open. 2019;2(12):e1918169.

18. Astor BC, Matsushita K, Gansevoort RT, van der Velde M, Woodward M, Levey AS, de Jong PE, Coresh $\mathrm{J}$; Chronic Kidney Disease Prognosis Consortium. Lower estimated glomerular filtration rate and higher albuminuria are associated with mortality and end-stage renal disease. A collaborative metaanalysis of kidney disease population cohorts. Kidney Int 2011 Jun;79(12): 1331-40.

19. Chronic Kidney Disease Prognosis Consortium; Matsushita K, van der Velde M, Astor BC, Woodward M, Levey AS, de Jong PE, Coresh J, Gansevoort RT. Association of estimated glomerular filtration rate and albuminuria with all-cause and cardiovascular mortality in general population cohorts: a collaborative meta-analysis. Lancet 2010 Jun 12;375(9731): 2073-81.

\section{Figures}




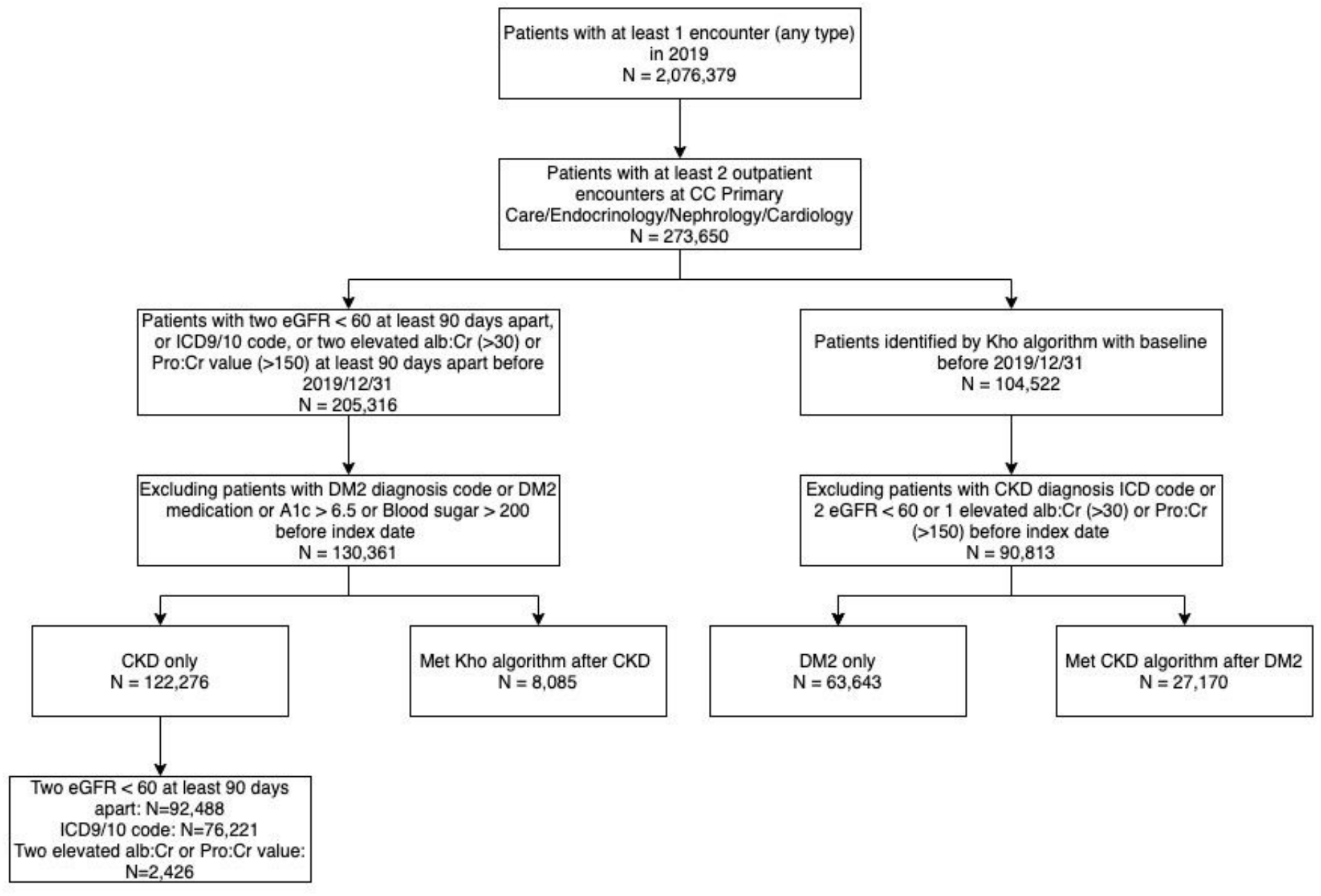

\section{Figure 1}

Flowchart of Patient Identification 